\title{
PERCUTANEOUS NEEDLE TENOTOMY FOR PONSETI TECHNIQUE IN THE MANAGEMENT OF CONGENITAL TALIPES EQUINOVARUS (CTEV)
}

\author{
RAHMAN MS ${ }^{1}$, ALAM MK ${ }^{2}$, SHAHIDUZZAMAN M ${ }^{3}$, RAHMAN A ${ }^{4}$
}

\begin{abstract}
:
Background: The Ponseti method has become established treatment of choice in the management of clubfoot i.e. congenital talipes equinovarus (CTEV). Tenotomy of Tendo-achillis often is required as last step of ponseti method of treatment. This procedural note describes a simple method of doing a percutaneous tenotomy of Tendo-achilles.
\end{abstract}

Methods: In Orthopedics OPD of Dhaka Medical College Hospital, Dhaka, percutaneous needle tenotomy was done in 70 feet of 52 patients from September 2013 to May 2014 by the same orthopedic surgeons for the management of CTEV by Ponseti technique.

Results: We have found this technique is very effective than the commonly practiced percutaneous blade tenotomy or open tenotomy.

Conclusion: This simple method of tenotomy using a wide bore needle during treatment of clubfoot in children can be a good surgical option.

Key words: Congenital Talipes Equinovarus (CTEV), Clubfoot, Ponseti Technique, Tenotomy, Tendo-Achilles.

J Dhaka Med Coll. 2014; 23(1) : 55-59.

\section{Introduction}

Clubfoot, congenital talipes equinovarus (CTEV) is a birth deformity occurring in one to three per thousand live births. ${ }^{1}$ Tenotomy is a common procedure for foot and ankle deformity surgeries for many years. Before percutaneous tenotomy evolved, for the treatment of clubfootAchilles tendons were divided by open operation ${ }^{2,3}$ e.g. with the tendon exposed in the wound. Lacking antiseptic wound techniques, infection supervened, \& healing was delayed. As a result, surgeons were not encouraged to perform open division.

Open tenotomy was subsequently aided by antiseptic and aseptic precautions, tendon exposure became safe and encouraged section with tendon overlap, by cutting obliquely, by Zlengthening in either sagittal or frontal planes, or by zigzag as devised by Poncet of Lyon to overcome post-traumatic shortening. ${ }^{4}$

At present, During the treatment of clubfoot deformity by Ponseti technique, Percutaneous / open tenotomies were performed in 85\% children. ${ }^{5-7}$ McGowan first described a minimally invasive technique for tenotomies. ${ }^{8}$ Currently, Percutaneous tenotomy with Surgical blade has been popularized for the management of clubfoot by many surgeon. ${ }^{6,9}$, ${ }^{10}$ For percutaneous tenotomy, Minkowitz first described using a large gauge needle for percutaneous lengthening of the Achilles tendon. ${ }^{11}$

In practice, Achilles tenotomies were performed when midfoot pirani score came to zero after serial casting by ponseti technique. It is performed either in the operating theatre

1. Dr. Mohammad Shahriar Rahman, Registrar, Department of Orthopaedic Surgery, Dhaka Medical College Hospital, Dhaka.

2. Dr. Md. Khorshed Alam, Assistant Professor, Department of Orthopaedic Surgery, Dhaka Medical College \& Hospital, Dhaka.

3. Prof. Md. Shahiduzzaman, Professor \& Head, Department of Orthopaedic Surgery, Dhaka Medical College \& Hospital, Dhaka.

4. Dr. Arebia Rahman, Resident Trainee, Department of Pathology, Dhaka Medical College, Dhaka.

Correspondence: Dr. Mohammad Shahriar Rahman, Registrar, Department of Orthopaedic Surgery, Dhaka Medical College Hospital, Dhaka. Cell phone: +8801711019087, Email: shujonsr@hotmail.com 
or out-patient department using a general anaesthesia or local anesthetic block. A small incision was made at the medial aspect of the Tendo-Achilles using a \#15 blade (Fig. 1) or similar. ${ }^{12,13}$ The tendon was then transected, and occasionally Posterior tibial vessels were also got injured. ${ }^{14}$ The incision was bandaged with or without simple interrupted sutures followed by application of Plaster cast. Postoperatively, wound was checked prior application of cast. If suture were used, they were removed at approximately two weeks.

This Needle tenotomy procedure provides a simplified sutureless technique to avoid ugly scar caused by open tenotomy procedure (Fig. 2 ). The percutaneous needle tenotomy described here, will offer an almost risk free procedure for the patient and a much simpler technique for the surgeon.

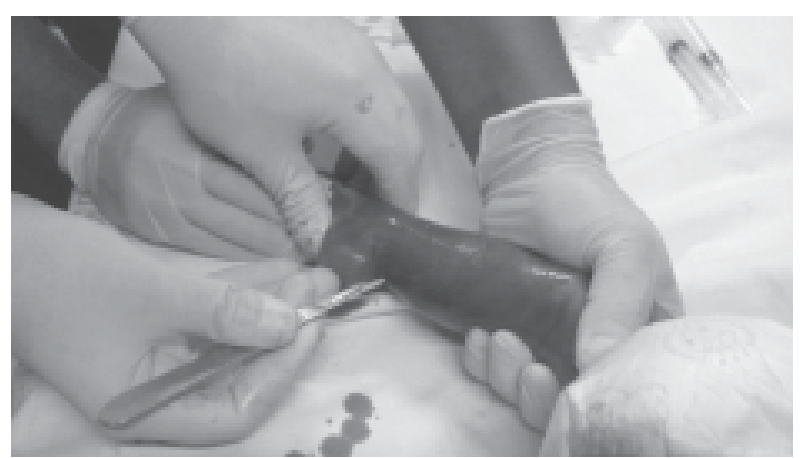

Fig.-1

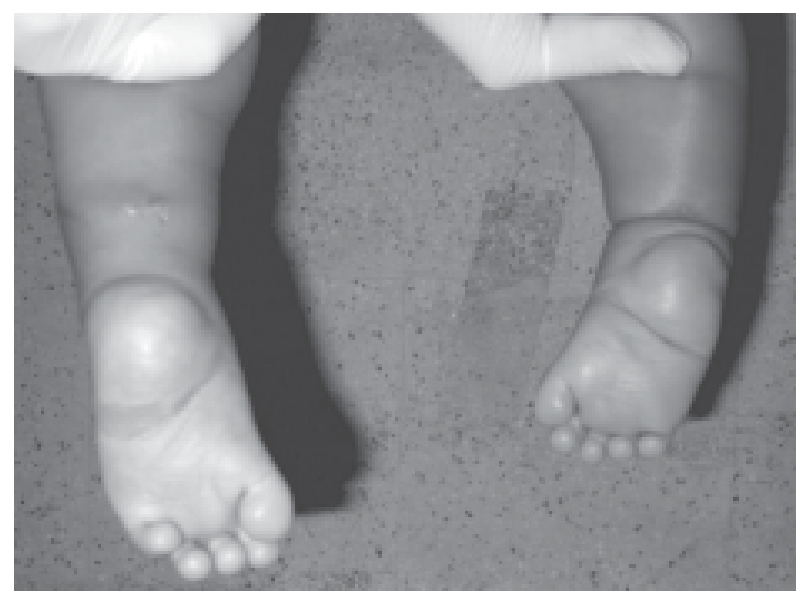

Fig.-2

\section{Methods}

In orthopedics OPD of Dhaka Medical College Hospital, Dhaka, percutaneous needle tenotomy was done in 70 feet of 52 patients from September 2013 to May 2014 by the same orthopedic surgeons for the management of CTEV by Ponseti technique.

In our study, modified percutaneous needle tenotomy technique utilizes a 19-gauge needle to perform release of Achilles tendon without suturing and the patient may get the foot without scar after the operation. This technique is performed in the OPD under a local anaesthesia block using 1\% Lidocaine. After the block is performed and the ankle prepped, tendo-Achillis is palpated by keeping the foot dorsiflexed (Fig. 3). To perform the tenotomy, needle is inserted from the medial border of the tendo-Achillis about one finger breadth proximal to the insertion of tendoAchillis or the posterior heel crease (Fig. 4).

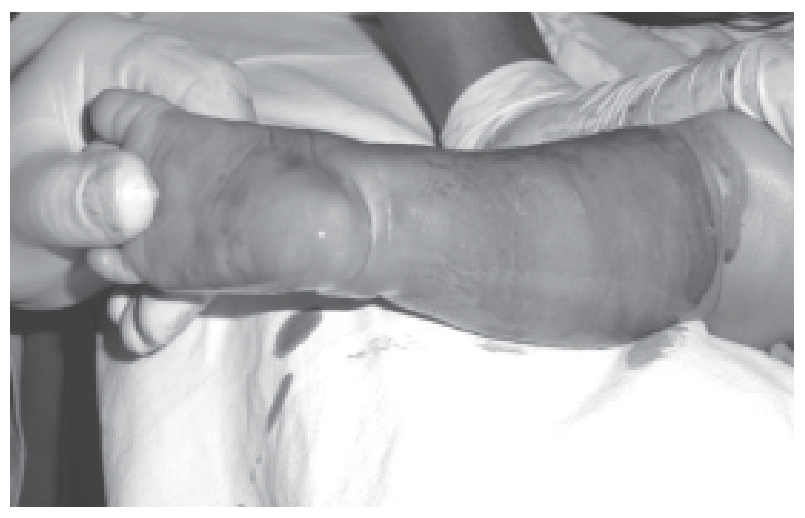

Fig.-3

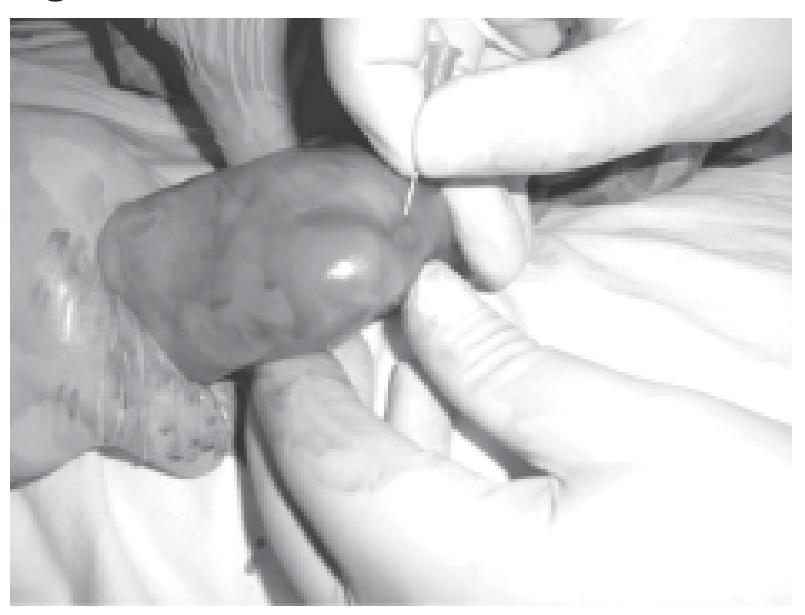

Fig.-4

Using the sharp beveled edge of the needle, a sweeping motion is carried out to transect the longitudinal fibers of the Achilles tendon (Fig. 5). A rolled cotton bandage to wrap the tenotomy 
wound was then applied. The patient is then sent back to her mother's lap for 15 minutes. Then, under aseptic precaution wound \& dorsiflexion were checked and a sterile bandage was applied on the tenotomy wound (Fig. 6). Above knee cast was then applied keeping the ankle on dorsiflexion position. Meticulous monitoring was done to check the capillary refilling of the toes during $\&$ after the application of cast. This cast is continued for 3 weeks.

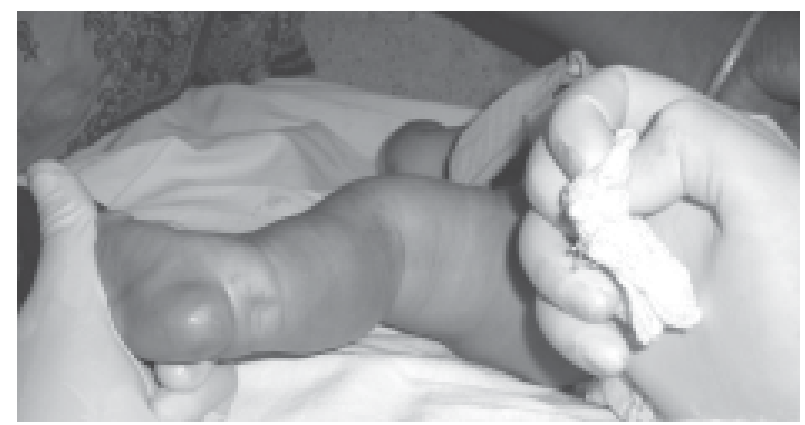

Fig.-5

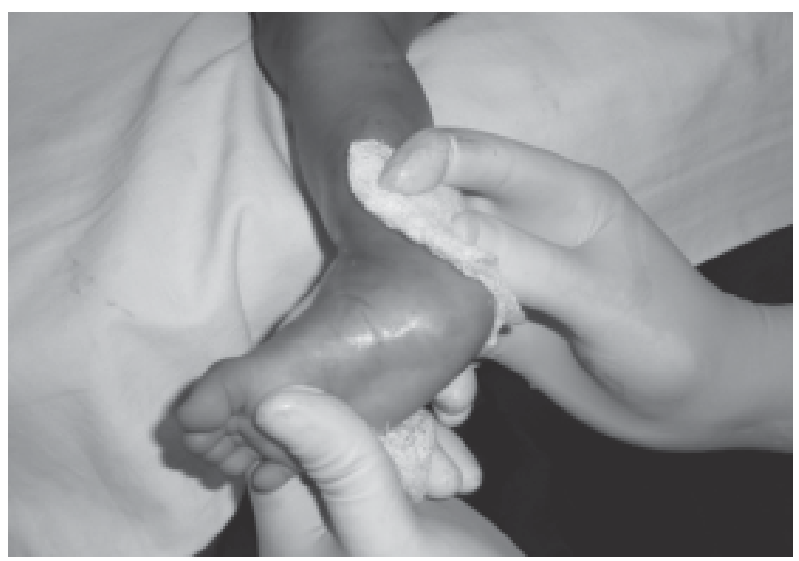

Fig.-6

\section{Results}

Among the patients, 32 (61.53\%) were male and $20(38.47 \%)$ were female (Table I). The male $\&$ female ratio was 1:0.62. The mean age of this study population was 4.02 months with a range of $1-26$ months. Among the patients, 41 cases $(78.84 \%)$ were in the age group of 1-6 months, 6 cases in the age group of $6-12$ months, 3 cases in the age group of 13-18 months, 1 case in the age group of 19-24 months, and 1 case in the age group of 25-30 months. Among these 52 patients, 47 patients (90\%) had no positive family history but 5 patients $(10 \%)$ had positive family history (two were sibling). Father of three patients and elder brother of two patients were found to have club foot.

\section{Table I}

Demographic profile of the study population $(n=52)$

\begin{tabular}{llcc}
\hline Variable & & Number & $\begin{array}{c}\text { Frequency } \\
\%\end{array}$ \\
\hline Gender & Male & 32 & $61.53 \%$ \\
& Female & 20 & $38.47 \%$ \\
Age & $1-6$ months & 41 & $78.84 \%$ \\
& 6-12 months & 6 & $11.53 \%$ \\
& $13-18$ months & 3 & $5.77 \%$ \\
& $19-24$ months & 1 & $1.93 \%$ \\
& 25-30 months & 1 & $1.93 \%$ \\
Family & Positive & 5 & $10 \%$ \\
\hline
\end{tabular}

Considering the number of involved foot, we found that 18 patients (34.61\%) had bi-lateral club feet $\& 34$ patients $(65.39 \%)$ presented with unilateral club foot (Table II). Among the unilateral cases, right sided unilateral club feet were 19 (36.53\%) \& left sided club feet were 15 (28.84\%).In this study, Pre tenotomy mean Pirani score was found 4.9 which 3 weeks after tenotomy \& final casting, became 0.75.The mean number of above knee POP cast applied on patients were 5.8 (range between 4-10).

\section{Table II}

Club foot profile of the study population $(n=52)$

\begin{tabular}{lcc}
\hline Variable & Frequency \% \\
\hline Affected foot & Bi-Lateral (18) & $34.61 \%$ \\
Uni-Lateral (34) & $65.39 \%$ \\
Mean Pre tenotomy Pirani score & 4.9 \\
Mean Number of POP Cast & 5.8 \\
Mean Post tenotomy Pirani score & 0.75 \\
Mean Follow up period & 4.5 months \\
\hline
\end{tabular}

Table III shows that in this study, 9 feet $(12.85 \%)$ out of 70 feet had some complications in context to the Tenotomy. Among these, 4 feet had procedural difficulties due to aberrant flattening of tendo Achilles. In 2 patients, there 
was minor bleeding from the vessel (which was controlled by applying pressure bandage over the tenotomy puncture wound for 12 minutes). Foot deformity was not corrected in 3 feet (Due to neglected type of CTEV which were later treated by soft tissue release surgery). In this study, we did not encounter any skin or soft tissue infection.

Table III

Complications of Percutaneous Needle Tenotomy $(n=70)$

\begin{tabular}{lcc}
\hline Complication & $\begin{array}{c}\text { Number of } \\
\text { foot }\end{array}$ & $\begin{array}{c}\text { Frequency } \\
\%\end{array}$ \\
\hline Bleeding & 2 & 2.85 \\
Infection & 0 & 0 \\
Difficult procedure & 4 & 5.71 \\
In corrected foot & 3 & 4.28 \\
\hline Total & 9 & $12.85 \%$ \\
\hline
\end{tabular}

\section{Discussion}

A total of 52 patients (70 clubfeet) were enrolled in this study. Among these 52 cases, male patients were $32(61.53 \%)$ whereas female patients were 20 (38.46\%). Previously Desai et al. ${ }^{15}$ reported that boys were more commonly affected than girls and his study ratio was 2:1. In 2007, Haft, Walker and Crawford also reported that $65 \%$ of their patients were male. ${ }^{16}$

Among those 52 patients, bilateral involvement was found in 18 patients (34.61\%), involvement of right foot was in 19 patients (36.53\%) and left foot involvement in 15 (28.84\%). Similar type of result was previously found by Laaveg and Ponseti. ${ }^{17}$ In another study, Yamamoto found that bilateral and unilateral affected cases were almost equal in numbers. ${ }^{18}$ Changulani et al. reported $52 \%$ bilateral and $48 \%$ unilateral club feet in his study. ${ }^{19}$

In this study population, 47 patients $(90 \%)$ had no family history but 5 patients (10\%) had positive family history. A positive family history also reported by Dietz in 2002 where he showed that one-third of patients had club foot. ${ }^{20}$

Pre-tenotomy mean Pirani score in this study was 4.9; Matuszewski, Gil and Karski found pretreatment Pirani score for their patients ranged from 4.5 to $6 .^{21}$ The mean number of plaster cast applied in our patients were 5.8 (range between 4-10). Dyer and Davis mentioned mean number of casts required during his study were 5.31 (2 to 9). ${ }^{22}$ Similar observation was demonstrated by Singh et al. ${ }^{23}$ According to study by Changulani et al. ${ }^{19}$, the mean Pirani score at presentation was 5.0 (4 to 6), at the end of initial treatment were 1.5 , mean number of casts required was six (2 to 12) which has similar outcome to this study. Pirani score after final cast was found 0.75 in our study. Matuszewski, Gil and Karski found 0.5 at 8 months to 1.5 Pirani score at 42 months after Achilles tenotomy. ${ }^{21}$

Few Complications were observed during \& after percutaneous needle Tenotomy. Complications were noted in 9 patients in 9 (12.85\%) feet. Among these 9 feet, 4 feet had procedural difficulties. In 2 patients, there was minor bleeding from the vessel. Foot deformity was not corrected in 3 feet (which were later treated by soft tissue release surgery). Changulani et al. observed $68 \%$ relapse after initial treatment. ${ }^{19}$ Janicki et al. also reported $31 \%$.recurrence that required additional treatment. ${ }^{24}$ None of the foot in our study required conversion or open tenotomy. There was no skin/soft tissue infection in any of our cases. Though, post tenotomy infection were reported in the studies of Lourenço and Morcuende in 2007 as well as in another study by Dyer and Davis. ${ }^{25,22}$

In this study, as we mainly focused on the percutaneous needle tenotomy, the mean follow up period for these patients were 4.5 months (1 to 8 month). Changulani et al. assessed the Ponseti technique for a mean period of followup of 18 months (6 to 30). ${ }^{19}$ Lourenço and Morcuende also followed-up clubfoot cases by mean period about 3.1 years (2.1 to 5.6 ) in their study. ${ }^{25}$ Both the author assessed the outcome of the Ponseti management in clubfoot patients.

\section{Conclusion}

This percutaneous needle tenotomy procedure offers a reliable and effective procedure at correcting club foot deformity by Ponseti technique. This technique is minimally invasive, scar less, simple to perform, can be 
performed on OPD basis and has very few complications. Although, conventional blade tenotomy achieves good correction, complications like damage to neurovascular structures leading to bleeding or pseudo aneurysms are not uncommon. ${ }^{14}$ In our series, (70 feet in 52 patients), 65 feet achieved optimum correction. Complications of needle percutaneous technique include difficult tenotomy in 4 feet, minor bleeding in 2 feet, failure to correct the deformity in 3 feet. There was no skin or soft tissue infection. None of the feet in our series required conversion or open tenotomy. The 19-gauge needle percutaneous tenotomy technique provides an effective means to perform Achilles tenotomy with a very low risk of failure. It is a simple surgical procedure for the OPD treatment of the indicated clubfoot who underwent correction by the Ponseti technique.

\section{References}

1. Pandey S. Neglected club foot. Foot 2002; 12: 123-41.

2. Thilenius MG. Medicinische und Chirurgische Bemerkungen. Frankfurt: Bronner; 1789. p. 335.

3. Michaelis C F. Ueber die Schwachung der Sehnen durch Einschneidung als einem Mittel bei manchen Gliederverunstaltungen. [Article in German]. [Abstract]. J Pract Heilk 1811; 33(5): 326.

4. Poncet A. De l'allongement dun tendon divist, avec Bcartement plus au moins considerable de ses deux bouts par des incisions en zigzag pratiquees sur ses bords: Allongement en accord $\&$ on. [Article in French]. [Abstract]. Gaz Hebdom de Med Chir 1891; 48: 575-7.

5. Bor N, Coplan JA, Herzenberg JE. Ponseti Treatment for idiopathic clubfoot: minimum 5-year follow-up. Clin Orthop Relat Res 2009; 467: 1263-70.

6. Maranho DAC, Nogueira-Barbosa MH, Simao MN, Volpon JB. Use of a large gauge needle for percutaneous sectioning of the Achilles tendon in congenital clubfoot. Acta Ortop Bras 2010; 18(5): 271-6.

7. Hussain N, Khan T, Ahmed A. Complete subcutaneous tenotomy of tendo-achilles in clubfoot patients - a four year follow up. J Surg 2004; 2(1): 17-9.

8. McGowan DD. Minimal incision tenotomy for hallux interphalangeal joint extensus. Clin Podiatr Med Surg 1991; 8: 1-8.

9. Herzenberg JE, Radler C, Bor N. Ponseti versus traditional methods of casting for idiopathic clubfoot. J Pediatr Orthop 2002; 22: 517-21.

10. Goksan SB. Ponseti technique for the correction of idiopathic clubfeet presenting up to 1 year of age: a preliminary study in children with untreated or complex deformities. Arch Orthop Trauma Surg 2006; 126: 15-21.

11. Minkowitz B, Finkelstein BI, Bleicher M. Percutaneous tendo-Achilles lengthening with a large-gauge needle: a modification of the Ponseti technique for correction of idiopathic clubfoot. J Foot Ankle Surg 2004; 43: 263-5.

12. Pandey S, Pandey AK. The classification of clubfoot a practical approach. Foot 2003; 13: 61-5.

13. Ponseti IV. Treatment of congenital club foot. J Bone Joint Surg Am 1992; 74: 448-54.

14. Dobbs MB, Gordon JE, Walton T, Schoenecker PL. Bleeding Complications Following tendo achilles percutaneous tenotomy in the Treatment of clubfoot deformity. J Pediatr Orthop. 2004, 24: 353-7.

15. Desai L, Oprescu F, Dimeo A, Mocuende J A. Bracing in the treatment of children with clubfoot: past, present, and future. The Iowa Orthopaedic Journal 2010; 30:15-30.

16. Haft G F, Walker CG, Crawford HA. Early clubfoot recurrence after use of the Ponseti method in a New Zealand population. J Bone Joint Surg Am 2007; 89(3): 487-493.

17. Laaveg SJ, Ponseti IV. Long term results of treatment of congenital clubfoot. J Bone Joint Surg [Br] 1980; 62(1): 23-31.

18. Yamamoto H. A clinical, genetic and epidemiologic study of congenital clubfoot. Jap. J. Human Genet 1979; 24: 37-44.

19. Changulani M, Garg NK, Rajagopal TS, Bass A, Nayagam SN, Sampath J, Bruce CE. Treatment of idiopathic clubfoot using the Ponseti method: Initial experience. $\mathrm{J}$ Bone Joint Surg $[\mathrm{Br}]$ 2006; 88(10): 1385-1387.

20. Dietz F. The genetics of idiopathic clubfoot. Cln Orthop Relat Res 2002; 401: 39-48.

21. Matuszewski L, Gil L, Karski J. Early results of treatment for congenital clubfoot using the Ponseti method. Eur J Orthop Surg Traumatol 2012; 22: 403-406.

22. Dyer PJ, Davis N. The role of Pirani scoring system in the management of club foot by the Ponseti method. J Bone Joint Sur [Br] 2006; 88(8): 1082-1084.

23. Singh NJ, Keshkar S, De P, Kumar R. Management of club foot by Ponseti techniqueour experience. IJPMR 2011; 22: 12-16.

24. Janicki JA, Wright JG, Weir S, Narayanan UG. A Comparison of ankle foot orthoses with foot abduction orthoses to prevent recurrence following correction of idiopathic clubfoot by the Ponseti method. J Bone Joint Surg [ $\mathrm{Br}]$ 2011; 93(5): 700-704.

25. Lourenco AF, Morcuende JA. Correction of neglected idiopathic club foot by Ponseti Method. J Bone Joint Surg [Br] 2007; 89(3): 378-381. 